\title{
不規則な配置をもつ杭径の異なる群杭に対する 横方向群杭効果の解析法

\author{
A METHOD OF ANALYSIS OF THE LATERAL RESISTANCE OF \\ PILE-GROUPS WITH DIFFERENT DIAMETERS OF \\ PILES DISPOSED ARBITRARILY
}

\author{
小 坪 清 真* 高 西 照 彦** \\ By Seima KOTSUBO and Teruhiko TAKANISHI
}

\section{1. まえがき}

群杭が横方向水平荷重を受けたときの挙動に関する実 験的研究は, 現在までいろいろ行われてきているが, 理 論的研究はあまりなされていない, 理論的研究としては すでに著者らが前論 ${ }^{1)}$ で言及した Penzien $ら^{2)}$, 杉村 ${ }^{3)}$, Poulos ${ }^{4)}$ の研究がその主なものとして挙げられよう.

著者らは前論 ${ }^{1,5}$ におおい, 群杭の横方向群杭効果に 関する理論的ならびに実験的研究を行い，著者らが導い た理論解と実験值とが 比較的よく一致することを示し た. 前論においては, まず上首地盤中に根入れされた単 杭がその杭頭に水平荷重を受けた時の杭および杭周辺地 盤の变形曲線の㛜密な解析解を求め, 次にこの解を用い て群杭がその杭頭に水平荷重を受けたときの各杭の変形 曲線を緩和法的な考え方に従って逐次近似的に求めて, これより 群杭効果の理論解を得ようとするものであっ た.この方法に従えば, 群杭を構成する杭の本数が多く なると, 各杭の変形曲線を求める手数が加速度的に増大 し, しかも煩雑で, そのらえ多大の計算時間を必要とす る.また，各杭の直径がまちまちであったり，あるいは 杭配置が不規則であるような場合については, さらにそ の煩雑さはいっそう増加する．そこで本論では上述の短 所を改良して, 多元連立方程式を解くだけで群杭効果を 容易に求めることができるという見通しのよい簡潔な群 杭効果の理論的解析法を新たに提案し, 本法による数值 計算結果の一例を示すとともに, 前論の計算結果と本論 のそれとを比較して, 両者がよく一致することを確かめ た. また, 著者らの行った群杭模型に対する群杭効果の 実験值とも比較して本論の方法の有用性を実証した.

\footnotetext{
* 正会員 工博 九州大学教授 工学部土木工学科

** 正会員 九州工業大学助教授 開発土木工学科
}

\section{2. 解析理論}

\section{(1) 群杭 効果}

図一1 に示寸群杭に対して, いま各杭の杭頭の連結を 断ち, しかし各杭の杭頭は回転拘束の状態にして,たと えば $i$ 杭の杭頭に $x$ 方向の単位水平荷重を加える. こ のとき $i$ 杭, $j$ 杭 $\cdots l$ 杭の $x$ 方向の杭頭水平変位を $\delta_{i i}{ }^{x x}, \delta_{j i}{ }^{x x}$ 等, $y$ 方向のそれを $\delta_{i i}{ }^{y x}, \delta_{j i}{ }^{y x}$ 等と表わ す、いまこれらの值が既知であるとすれば, 群杭効果は 次のよらにしてこれを容易に求めることができる.すな わち, $N$ 本から構成された群杭の各杭の杭頭に, それぞ れ $x$ および $y$ 方向の水平荷重を加えて, 各杭の $x$ 方 向の杭頭変位を $1, y$ 方向のそれを 0 にするに必要な荷 重を，それぞれ $Q_{i}{ }^{x}, Q_{i}{ }^{y}(i=1,2, \cdots, N)$ とおけば, $Q_{i}{ }^{x}, Q_{i}{ }^{y}$ は次の連立一次方程式の解として求めること ができる.
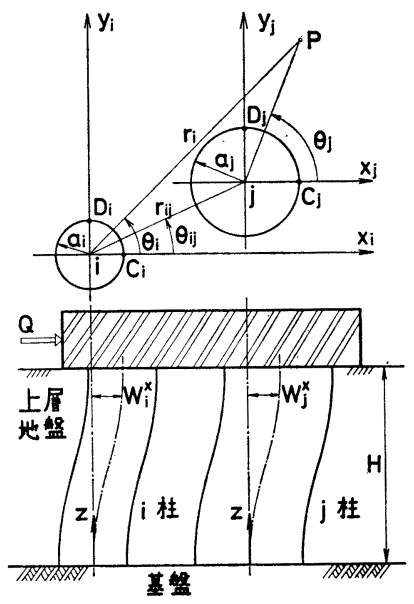

図一1群杭一地盤系および坐標系 


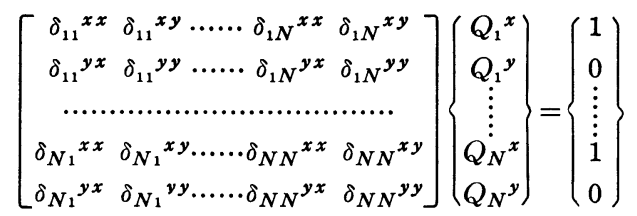

したがって，単杭の杭頭を 1 だけ変位させるのに必要 な水平荷重をたとえば $i$ 杭について $Q_{i 0}$ とすれば, 群 杭効果は次式から得られる.

$$
e_{N}=\frac{\sum_{i=1}^{N} Q_{i}{ }^{x}}{\sum_{i=1}^{N} Q_{i 0}}
$$

また, $y$ 方向の群杭効果については, 式 (1) の右辺に おいて 1 を 0 に，0を 1 に変えた式を解いて,

$$
e_{N}{ }^{y}=\frac{\sum_{i=1}^{N} Q_{i}{ }^{y}}{\sum_{i=1}^{N} Q_{i 0}}
$$

から求めればよい。

以上のことから問題は結局, 各杭に対する変位の影響 係数 $\delta_{i j}{ }^{x y}$ 等を求めることに帰着される. 本論ではそれ を以下に示すようにして求めた.

\section{（2）単杭の場合の変形曲線}

水平方向に無限の拡がりをもつ上層地盤中に 1 本の杭 が打設された場合を考えて，この単杭の杭頭に単位の水 平荷重を加える.このときこの単杭について, 杭下端固 定, 杭頭回転拘束の条件のもとでの, 杭とその周辺地盤

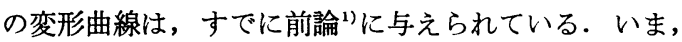
ここにその結果のみを示せば次のとおりである.すなわ ち, 杭の弾性変形を支配する微分方程式と杭周面上にお ける連続の条件とを満足する解として,杭の変形曲線は,

$$
\begin{aligned}
w(z)= & \frac{32 H^{3}}{\pi^{4} E I} \sum_{m=1,3,5, \ldots}^{\infty}(-1)^{(m-1) / 2} \\
& \cdot m^{-4} \bar{Y}_{m} \sin \frac{m \pi z}{2 H} \cdots \ldots \ldots \ldots \ldots \ldots
\end{aligned}
$$

地盤の半径方向の変形曲線は,

$$
\begin{aligned}
\xi(r, \theta, z)= & \frac{32 H^{3}}{\pi^{4} E I} \sum_{m=1,3,5, \cdots}^{\infty}(-1)^{(m-1) / 2} \\
& \cdot m^{-4} \bar{Y}_{m} U_{m}(r) \cos \theta \sin \frac{m \pi z}{2 H} \cdots
\end{aligned}
$$

地盤の円周方向の変形曲線は,

$$
\begin{aligned}
\zeta(r, \theta, z)= & \frac{32 H^{3}}{\pi^{4} E I} \sum_{m=1,3,5, \cdots}^{\infty}(-1)^{(m-1) / 2} \\
& \cdot m^{-4} \bar{Y}_{m} V_{m}(r) \sin \theta \sin \frac{m \pi z}{2 H} \cdots
\end{aligned}
$$

と表わされる.

ここに,

$$
\bar{Y}_{m}=1 /\left(1+\alpha m^{-2} \Omega_{m}\right)
$$

$$
\left.\begin{array}{rl}
U_{m}(r)= & \frac{1}{\eta_{r}}\left[K_{1}\left(\eta_{a} \eta_{r}\right)+\eta_{a} \eta_{r} K_{0}\left(\eta_{a} \eta_{r}\right)\right. \\
& \left.-\psi_{m} K_{1}\left(\psi_{a} \psi_{r}\right)\right] \\
V_{m}(r)= & \frac{1}{\eta_{r}}\left[K_{1}\left(\eta_{a} \eta_{r}\right)-\psi_{m}\left\{K_{1}\left(\psi_{a} \psi_{r}\right)\right.\right. \\
& \left.\left.+\psi_{a} \psi_{r} K_{0}\left(\psi_{a} \psi_{r}\right)\right\}\right]
\end{array}\right\}(8)
$$

$H$ は上層地盤の厚さ, $\mu$ は上層地盤のせん断弾性定 数, $\nu$ はポアソン比, $a$ は杭半径, $E I$ は杭の曲げ剛性, $r, \theta$ は極座標, $z$ は基盤からの高さ, $K_{n}\left(\eta_{a}\right)$ は第 2 種 第 $n$ 次の変形ベッセル関数である.

\section{（3）群杭の場合の地盤の変形曲線}

群杭においてその頭部の連結を断ち, しかし各杭の杭 頭は回転拘束の状態のままで, たとえば $i$ 杭の杭頭に $x$ 方向単位水平荷重を加えたとき, 各杭および杭周辺地盤 の変形曲線を表わす解析解が得られれば, これを用いて （1）に述べた変位の影響係数を求めること，したがっ て, 群杭効果を導くことは容易である. さて, $i$ 杭が変 形するとその周辺地盤が変形を生じ, これが $i$ 杭以外の 杭の変形を惹起する.この $i$ 杭以外の杭の変形がまた $i$ 杭に影響を及ぼす. 寸なわち, 各杭の間には地盤を介し て相互作用が生ずる. 本論では $i$ 杭の杭頭に $x$ 方向単 位水平荷重を加えたときの杭周辺地盤中の任意点 $P$ (図 -1 参照）の変位を， $i$ 杭自身の変形による地盤変位と $i$ 杭以外の杭の変形による地盤変位とに分けて考えて, この両者を加え合わせることによって $P$ 点の地盤変位 を表わすことにする.

各杭が単独で存在して他の杭の影響をうけずに変形す るときの 周辺地盤の変形曲線はそれれぞれ式 (5)，(6) によってこれを求めることができる．しかし，実際には 各杭が同時に存在して相互作用を及ぼし合うので，いま 求めた地盤の変形曲線をただ単にそのまま重ね合わせた だけでは, 本論で求めようとする真の地盤の変形曲線を 表わすことはできない. したがって, 本論においては, $i$ 杭の杭頭に $x$ 方向単位水平荷重を加えたときの杭周辺 地盤中の任意点 $P$ の半径方向および 円周方向の変形曲 線の表示式として, 次式に示すように, 上記の単独杭の 変形による周辺地盤の変形曲線を表わす式の各項に, そ れぞれ末定係数を掛けて, それらを $i$ 杭および $i$ 杭以外 のすべての杭について重ね合わせたものを採用した. 
$i$ 杭を基準に考えた場合の $P$ 点の半径方向変形とし $\tau$,

$$
\begin{aligned}
\xi_{P}= & \xi_{P i}+\sum_{j \neq i} \xi_{P j} \\
= & \sum_{m=1,3,5 \cdots}^{\infty}\left\{U_{m}^{i x}\left(r_{i}\right) \cos \theta_{i}\right. \\
& \left.+U_{m}^{i y}\left(r_{i}\right) \sin \theta_{i}\right\} \sin \frac{m \pi z}{2 H} \\
& +\sum_{j \neq i} \sum_{m=1,3,5 \ldots}^{\infty}\left[\left\{U_{m}^{j x}\left(r_{j}\right) \cos \theta_{j}\right.\right. \\
& \left.+U_{m}{ }^{j y}\left(r_{j}\right) \sin \theta_{j}\right\} \cos \left(\theta_{j}-\theta_{i}\right) \\
& -\left\{V_{m}{ }^{j x}\left(r_{j}\right) \sin \theta_{j}\right. \\
& \left.\left.-V_{m}{ }^{j y}\left(r_{j}\right) \cos \theta_{j}\right\} \sin \left(\theta_{j}-\theta_{i}\right)\right] \sin \frac{m \pi z}{2 H}
\end{aligned}
$$

円周方向変形として,

$$
\begin{aligned}
\zeta_{P}= & \zeta_{P i}+\sum_{i \neq i} \zeta_{P j} \\
= & \sum_{m=1,3,5, \ldots}^{\infty}\left\{V_{m}^{i x}\left(r_{i}\right) \sin \theta_{i}\right. \\
& \left.-V_{m}^{i y}\left(r_{i}\right) \cos \theta_{i}\right\} \sin \frac{m \pi z}{2 H} \\
& +\sum_{j \neq i} \sum_{m=1,3,5, \ldots}^{\infty}\left[\left\{U_{m}^{j x}\left(r_{j}\right) \cos \theta_{j}\right.\right. \\
& \left.+U_{m}^{j y}\left(r_{j}\right) \sin \theta_{j}\right\} \sin \left(\theta_{j}-\theta_{i}\right) \\
& +\left\{V_{m}^{j x}\left(r_{j}\right) \sin \theta_{j}\right. \\
& \left.\left.-V_{m}^{j y}\left(r_{j}\right) \cos \theta_{j}\right\} \cos \left(\theta_{j}-\theta_{i}\right)\right] \sin \frac{m \pi z}{2 H}
\end{aligned}
$$

上式の右辺第 1 項は $i$ 杭自身の変形に基づく地盤変形 を, 第 2 項以下は $i$ 杭以外の杭の変形による地盤変形を 表わしている.

ここに,

$$
\begin{aligned}
U_{m}^{i x}\left(r_{i}\right)= & \frac{1}{\eta_{r i}}\left[A _ { m } ^ { i x } \left\{K_{1}\left(\eta_{a i} \eta_{r i}\right)\right.\right. \\
& \left.+\eta_{a i} \eta_{r i} K_{0}\left(\eta_{a i} \eta_{r i}\right)\right\} \\
& \left.+B_{m}^{i x} K_{1}\left(\psi_{a i} \psi_{r i}\right)\right] \\
V_{m}{ }^{i x}\left(r_{i}\right)= & \frac{1}{\eta_{r i}}\left[A_{m}{ }^{i x} K_{1}\left(\eta_{a i} \eta_{r i}\right)\right. \\
& +B_{m}^{i x}\left\{K_{1}\left(\phi_{a i} \psi_{r i}\right)\right. \\
& \left.\left.+\phi_{a i} \psi_{r i} K_{0}\left(\psi_{a i} \psi_{r i}\right)\right\}\right] \\
& \left\{\begin{array}{l}
x=x, y \\
i=1,2, \cdots, N
\end{array}\right. \\
\phi_{a i}=\frac{m \pi}{2} & \frac{a_{i}}{H}, \eta_{a i}=\sqrt{\frac{1-2 \nu}{2(1-\nu)}} \psi_{a i} \\
\phi_{r i}=\eta_{r i}= & \frac{r_{i}}{a_{i}} \quad(i=1,2, \cdots, N)
\end{aligned}
$$

$a_{i}(i=1,2, \cdots, N)$ は各杭の杭半径である. 未定係数 $A_{m}{ }^{i x}$ 等は杭の弾性変形曲線および境界条件を満足する ように定める.このことについては以下に詳論する.

\section{（4）杭に働く土圧}

上層地盤の応力は次式によって求められる.

$$
\left.\begin{array}{l}
\sigma_{P}=\lambda\left(\frac{\partial \xi_{P}}{\partial r_{i}}+\frac{\xi_{P}}{r_{i}}+\frac{1}{r_{i}} \frac{\partial \zeta_{P}}{\partial \theta_{i}}\right)+2 \mu \frac{\partial \xi_{P}}{\partial r_{i}} \\
\tau_{P}=\mu\left(\frac{1}{r_{i}} \frac{\partial \xi_{P}}{\partial \theta_{i}}+\frac{\partial \zeta_{P}}{\partial r_{i}}-\frac{\zeta_{P}}{r_{i}}\right)
\end{array}\right\}
$$

ここに $\lambda, \mu$ はラーメの定数である. したがって，たと えば $i$ 杭の単位長さ当りに働く $x$ 方向の土圧は,

$$
P_{i}^{x}(z)=\int_{-\pi}^{\pi}\left[\sigma_{P} \cos \theta_{i}-\tau_{P} \sin \theta_{i}\right]_{r_{i}=a_{i}} a_{i} d \theta_{i}
$$

$y$ 方向の土圧は,

$$
P_{i}^{y}(z)=\int_{-\pi}^{\pi}\left[\sigma_{P} \sin \theta_{i}+\tau_{P} \cos \theta_{i}\right]_{r_{i}=a_{i}} a_{i} d \theta_{i}
$$

によって与えられる. 上式に式 (13)，(14）を代入する 之,

$$
\begin{aligned}
& P_{i}^{x}(z)=\sum_{m=1,3,5, \ldots}^{\infty} \frac{m^{2} \pi^{3}}{4} \frac{a_{i}{ }^{2}}{H^{2}} \mu\left\{-A_{m}{ }^{i x} K_{1}\left(\eta_{a i}\right)\right. \\
& \left.+B_{m}{ }^{i x} K_{1}\left(\psi_{a i}\right)\right\} \sin \frac{m \pi z}{2 H} \\
& -\frac{1}{2} \sum_{j \neq i} \frac{a_{i}}{a_{j}} \mu \sum_{m=1,3,5, \ldots}^{\infty} \int_{-\pi}^{\pi}\left[A _ { m } { } ^ { j x } \eta _ { a j } { } ^ { 2 } \left\{K_{3}\left(\eta_{a j} \eta_{r j}\right)\right.\right. \\
& \cdot \cos \left(3 \theta_{j}-\theta_{i}\right)+K_{1}\left(\eta_{a j} \eta_{r j}\right) \cos \left(\theta_{j}-\theta_{i}\right) \\
& \left.+\frac{2}{1-2 \nu} K_{1}\left(\eta_{a j} \eta_{r j}\right) \cos \theta_{j} \cos \theta_{i}\right\} \\
& +B_{m}{ }^{j x} \psi_{a j}{ }^{2}\left\{K_{3}\left(\psi_{a j} \psi_{r j}\right) \cos \left(3 \theta_{j}-\theta_{i}\right)\right. \\
& \left.-K_{1}\left(\psi_{a j} \psi_{r j}\right) \cos \left(\theta_{j}-\theta_{i}\right)\right\} \\
& +A_{m}^{j} y_{\eta_{a j}{ }^{2}}\left\{K_{3}\left(\eta_{a j} \eta_{r j}\right) \sin \left(3 \theta_{j}-\theta_{i}\right)\right. \\
& -K_{1}\left(\eta_{a j} \eta_{r j}\right) \sin \left(\theta_{j}-\theta_{i}\right) \\
& \left.+\frac{2}{1-2 \nu} K_{1}\left(\eta_{a j} \eta_{r j}\right) \sin \theta_{j} \sin \theta_{i}\right\} \\
& +B_{m}^{j y} \psi_{a j}{ }^{2}\left\{K_{3}\left(\psi_{a j} \psi_{r j}\right) \sin \left(3 \theta_{j}-\theta_{i}\right)\right. \\
& \left.\left.+K_{1}\left(\psi_{a j} \psi_{r j}\right) \sin \left(\theta_{j}-\theta_{i}\right)\right\}\right]_{r_{i}=a_{i}} d \theta_{i} \\
& \cdot \sin \frac{m \pi z}{2 H} \\
& P_{i}^{y}(z)=\sum_{m=1,3,5, \ldots}^{\infty} \frac{m^{2} \pi^{3}}{4} \frac{a_{i}{ }^{2}}{H^{2}} \mu\left\{-A_{m}{ }^{i y} K_{1}\left(\eta_{a i}\right)\right. \\
& \left.+B_{m}{ }^{i y} K_{1}\left(\psi_{a i}\right)\right\} \sin \frac{m \pi z}{2 H} \\
& -\frac{1}{2} \sum_{j \neq i} \frac{a_{i}}{a_{j}} \mu \sum_{m=1,3,5, \ldots}^{\infty} \int_{-\pi}^{\pi}\left[A_{m}^{j x} \eta_{a j}{ }^{2}\right. \\
& \cdot\left\{K_{3}\left(\eta_{a j} \eta_{r j}\right) \sin \left(3 \theta_{j}-\theta_{i}\right)+K_{1}\left(\eta_{a j} \eta_{r j}\right)\right. \\
& \cdot \sin \left(\theta_{j}-\theta_{i}\right)+\frac{2}{1-2 \nu} K_{1}\left(\eta_{a j} \eta_{r j}\right) \cos \theta_{j} \\
& \left.\cdot \sin \theta_{i}\right\}+B_{m}{ }^{j x} \phi_{a j}{ }^{2}\left\{K_{3}\left(\psi_{a j} \psi_{r j}\right)\right. \\
& \left.\cdot \sin \left(3 \theta_{j}-\theta_{i}\right)-K_{1}\left(\phi_{a j} \phi_{r j}\right) \sin \left(\theta_{j}-\theta_{i}\right)\right\} \\
& +A_{m}^{j y \eta_{a j}{ }^{2}}\left\{-K_{3}\left(\eta_{a j} \eta_{r j}\right) \cos \left(3 \theta_{j}-\theta_{i}\right)\right. \\
& +K_{1}\left(\eta_{a j} \eta_{r j}\right) \cos \left(\theta_{j}-\theta_{i}\right)
\end{aligned}
$$




$$
\begin{aligned}
& \left.+\frac{2}{1-2 \nu} K_{1}\left(\eta_{a j} \eta_{r j}\right) \sin \theta_{j} \sin \theta_{i}\right\} \\
& +B_{m}{ }^{j y} \psi_{a j}{ }^{2}\left\{-K_{3}\left(\psi_{a j} \psi_{r j}\right) \cos \left(3 \theta_{j}-\theta_{i}\right)\right. \\
& \left.\left.-K_{1}\left(\psi_{a j} \psi_{r j}\right) \cos \left(\theta_{j}-\theta_{i}\right)\right\}\right]_{r_{i}=a_{i}} d \theta_{i} \\
& \cdot \sin \frac{m \pi z}{2 H} \ldots \ldots \ldots \ldots \ldots \ldots \ldots \ldots \ldots \ldots \ldots \ldots \ldots \ldots \ldots \ldots \ldots
\end{aligned}
$$

上式で，それぞれ第 1 項は $i$ 杭自身の変形による土圧, 第 2 項以下は $i$ 杭以外の杭の変形による土圧である.

ここで 付録 I を参照すれば, 式 $(18)^{\prime},(19)^{\prime}$ の右辺 第 2 項は次のように書ける.

式 (18)' の右辺第 2 項

$$
\begin{aligned}
=- & \sum_{j \neq i} \pi \mu \frac{a_{i}}{a_{j}} \sum_{m=1,3,5, \ldots}^{\infty}\left[A _ { m } ^ { j x } \eta _ { a i } { } ^ { 2 } \left\{F\left(\eta_{a i}, \eta_{r i j}\right) \cos 2 \theta_{i j}\right.\right. \\
& -\frac{2(1-\nu)}{1-2 \nu} I_{1}\left(\eta_{a i}\right) K_{0}\left(\eta_{a i} \eta_{r i j}\right) \\
& \left.-\frac{1}{1-2 \nu} I_{1}\left(\eta_{a i}\right) K_{2}\left(\eta_{a i} \eta_{r i j}\right) \cos 2 \theta_{i j}\right\} \\
& +B_{m}^{j x} \psi_{a i}{ }^{2}\left\{F\left(\psi_{a i}, \psi_{r i j}\right) \cos 2 \theta_{i j}\right. \\
& \left.+I_{1}\left(\psi_{a i}\right) K_{0}\left(\psi_{a i} \psi_{r i j}\right)\right\} \\
& +A_{m}{ }^{j y_{\eta_{a i}}}\left\{F\left(\eta_{a i}, \eta_{r i j}\right) \sin 2 \theta_{i j}\right. \\
& \left.-\frac{1}{1-2 \nu} I_{1}\left(\eta_{a i}\right) K_{2}\left(\eta_{a i} \eta_{r i j}\right) \sin 2 \theta_{i j}\right\} \\
& \left.+B_{m}{ }^{j y} \psi_{a i}{ }^{2}\left\{F\left(\psi_{a i}, \phi_{r i j}\right) \sin 2 \theta_{i j}\right\}\right] \sin \frac{m \pi z}{2 H}
\end{aligned}
$$

式 (19)' の右辺第 2 項

$$
\begin{aligned}
& =-\sum_{j \neq i} \pi \mu \frac{a_{i}}{a_{j}} \sum_{m=1,3,5, \cdots}^{\infty}\left[A _ { m } { } ^ { j x } \eta _ { a i } { } ^ { 2 } \left\{F\left(\eta_{a i}, \eta_{r i j}\right) \sin 2 \theta_{i j}\right.\right. \\
& \left.-\frac{1}{1-2 \nu} I_{1}\left(\eta_{a i}\right) K_{2}\left(\eta_{a i} \eta_{r i j}\right) \sin 2 \theta_{i j}\right\} \\
& +B_{m}^{j x} \psi_{a i}{ }^{2}\left\{F\left(\psi_{a i}, \psi_{r i j}\right) \sin 2 \theta_{i j}\right\} \\
& +A_{m}^{j y} \eta_{a i}{ }^{2}\left\{-F\left(\eta_{a i}, \eta_{r i j}\right) \cos 2 \theta_{i j}\right. \\
& -\frac{2(1-\nu)}{1-2 \nu} I_{1}\left(\eta_{a i}\right) K_{0}\left(\eta_{a i} \eta_{r i j}\right) \\
& \left.+\frac{1}{1-2 \nu} I_{1}\left(\eta_{a i}\right) K_{2}\left(\eta_{a i} \eta_{r i j}\right) \cos 2 \theta_{i j}\right\} \\
& +B_{m}^{j y} \phi_{a i}{ }^{2}\left\{-F\left(\phi_{a i}, \phi_{r i j}\right) \cos 2 \theta_{i j}\right. \\
& \left.\left.+I_{1}\left(\psi_{a i}\right) K_{0}\left(\phi_{a i} \psi_{r i j}\right)\right\}\right] \sin \frac{m \pi z}{2 H} \\
& \text { ここに, } \eta_{r i j}=r_{i j} / a_{i}
\end{aligned}
$$

\section{（5）杭の変形曲線}

群杭を構成する各杭の弾性変形を支配する微分方程式 は, $x$ 方向の変形に対して,

$$
\begin{array}{r}
E_{i} I_{i} \frac{d^{4}}{d z^{4}}\left\{w_{i}^{x}(z)\right\}=P_{i}^{x}(z)+q_{i}^{x}(z) \\
(i=1,2, \cdots, N)
\end{array}
$$

$y$ 方向に対しては,

$$
\begin{array}{r}
E_{i} I_{i} \frac{d^{4}}{d z^{4}}\left\{w_{i}^{y}(z)\right\}=P_{i}^{y}(z)+q_{i}^{y}(z) . \\
(i=1,2, \cdots, N)
\end{array}
$$

と表わされる. ここに, $E_{i} I_{i}$ は $i$ 杭の曲げ剛性, $w_{i}{ }^{x}$ $(z), w_{i}^{y}(z)$ は $i$ 杭の $x, y$ 方向の水平変位, $P_{i}^{x}(z)$, $P_{i}^{y}(z)$ は $i$ 杭の $x, y$ 方向に働く単位墚さ当りの土圧, ${q_{i}}^{x}(z), q_{i}{ }^{y}(z)$ は $i$ 杭に働く $x, y$ 方向外力である.

さて, いま杭長を $H$ として, $i$ 杭のみにその杭頭に $x$ 方向の単位の外力が加わる場合を考える. 変位 $w_{i}{ }^{x}$ $(z), w_{i}^{y}(z)$ および外力 $q_{i}^{x}(z)$ をフーリエ sine 級数 に展開すれば,

$$
\left.\begin{array}{l}
w_{i}^{x}(z)=\sum_{m=1,3,5, \cdots}^{\infty} Y_{m}^{i x} \sin \frac{m \pi z}{2 H} \\
w_{i}{ }^{y}(z)=\sum_{m=1,3,5, \cdots}^{\infty} Y_{m}^{i y} \sin \frac{m \pi z}{2 H}
\end{array}\right\} \ldots \ldots \ldots .
$$

と表わせる.ここに $Y_{m}^{i x}, Y_{m}^{i y}$ は境界条件から定まる 末定係数である.また，いまの場合，

$$
\left.\begin{array}{l}
q_{i}^{y}(z)=0 \\
q_{j}^{x}(z)=q_{j}^{y}(z)=0 \quad(j \neq i)
\end{array}\right\}
$$

である.

後に示す式 (35) の関係を考慮して, 式 (24) （26） お よび式 (18)'，(19)' を式 (22)，(23) に代入して整理す れば, 次式が得られる。

$$
\begin{aligned}
& Y_{m}^{s x}+\alpha_{s} m^{-2}\left\{K_{1}\left(\eta_{a s}\right)+\psi_{m}^{s} K_{1}\left(\psi_{a s}\right)\right\} A_{m}^{s x} \\
& +\sum_{j \neq s} \frac{a_{s}}{a_{j}} \alpha_{s} m^{-2}\left[\left\{\frac{1-2 \nu}{2(1-\nu)} F\left(\eta_{a s}, \eta_{r s j}\right)\right.\right. \\
& -\psi_{m}^{j} F\left(\psi_{a s}, \psi_{r s j}\right) \\
& \left.-\frac{1}{2(1-\nu)} I_{1}\left(\eta_{a s}\right) K_{2}\left(\eta_{a s} \eta_{r s j}\right)\right\} \cos 2 \theta_{s j} \\
& -I_{1}\left(\eta_{a s}\right) K_{0}\left(\eta_{a s} \eta_{r s j}\right) \\
& \left.-\psi_{m}^{j} I_{1}\left(\psi_{a s}\right) K_{0}\left(\psi_{a s} \psi_{r s j}\right)\right] A_{m}^{j x} \\
& +\sum_{j \neq s} \frac{a_{s}}{a_{j}} \alpha_{s} m^{-2}\left[\left\{\frac{1-2 \nu}{2(1-\nu)} F\left(\eta_{a s}, \eta_{r s j}\right)\right.\right. \\
& -\psi_{m}^{j} F\left(\phi_{a s}, \phi_{r s j}\right) \\
& \left.\left.-\frac{1}{2(1-\nu)} I_{1}\left(\eta_{a s}\right) K_{2}\left(\eta_{a s} \eta_{r s j}\right)\right\} \sin 2 \theta_{s j}\right] A_{m}^{j y} \\
& =\left\{\begin{array}{cc}
(-1)^{(m-1) / 2} \frac{32 H^{3}}{\pi^{4} m^{4} E_{i} I_{i}} & (s=i) \\
0 & (s \neq i)
\end{array}\right. \\
& Y_{m}{ }^{s y}+\alpha_{s} m^{-2}\left\{K_{1}\left(\eta_{a s}\right)+\psi_{m}{ }^{s} K_{1}\left(\psi_{a s}\right)\right\} A_{m}{ }^{s y} \\
& +\sum_{j \neq s} \frac{a_{s}}{a_{j}} \alpha_{s} m^{-2}\left[\left\{\frac{1-2 \nu}{2(1-\nu)} F\left(\eta_{a s}, \eta_{r s j}\right)\right.\right. \\
& -\psi_{m}{ }^{j} F\left(\phi_{a s}, \phi_{r s j}\right) \\
& \left.\left.-\frac{1}{2(1-\nu)} I_{1}\left(\eta_{a s}\right) K_{2}\left(\eta_{a s} \eta_{r s j}\right)\right\} \sin 2 \theta_{s j}\right] A_{m}{ }^{j x}
\end{aligned}
$$




$$
\begin{aligned}
& \quad+\sum_{j \neq s} \frac{a_{s}}{a_{j}} \alpha_{s} m^{-2}\left[-\left\{\frac{1-2 \nu}{2(1-\nu)} F\left(\eta_{a s}, \eta_{r s j}\right)\right.\right. \\
& -\psi_{m}{ }^{j} F\left(\phi_{a s}, \phi_{r s j}\right) \\
& \left.-\frac{1}{2(1-\nu)} I_{1}\left(\eta_{a s}\right) K_{2}\left(\eta_{a s} \eta_{r s j}\right)\right\} \cos 2 \theta_{s j} \\
& -I_{1}\left(\eta_{a s}\right) K_{0}\left(\eta_{a s} \eta_{r s j}\right) \\
& \left.\quad-\psi_{m}{ }^{j} I_{1}\left(\phi_{a s}\right) K_{0}\left(\psi_{a s} \psi_{r s j}\right)\right] A_{m}^{j y}=0 \cdots \cdots \\
& こ こ に, \quad(s=1,2, \cdots, N) \\
& \alpha_{s}=\frac{4 H^{2} a_{s}{ }^{2}}{\pi} \frac{\mu}{E_{s} I_{s}}(s=1,2, \cdots, N) \cdots \cdots
\end{aligned}
$$

また, $i$ 杭の頭部に $y$ 方向の単位水平荷重を加えたと きは，式 (27)，(28）において，その右辺を互いに置換 した式が成り立つ.

\section{（6）境界条件}

各杭について, その杭周面上各点の変位は, それに接 する土粒子の変位に等しくなければならない.しかし， この境界条件を各杭について厳密に満足するように末定 係数を求めることは, 非常に煩雑であり, しかもあまり 実用的であるとはいいにくい. 本論では，たとえば $i$ 杭 については, $i$ 杭の中心位置における変位を採用するこ とによって, $i$ 杭以外の杭が $i$ 杭に与える影響を近似的 に評価した.

また，式 (13)，(14) 自身もこのままでは正確な地盤 変形を与える式とはいえず, 厳密には式 (13), (14) に さらに $\cos 2 \theta, \sin 2 \theta, \cdots$ のそれぞれに末定係数を掛け た項をつけ加えなければならないが，本論では煩雑さと 実用性を考慮して, これらの項をいっさい省略した.

しかし，以上の近似的取扱いに対して，それが群杭効 果に及ぼす影響は, 後に示すように群杭中の最小の杭中 心点間距離 $l$ と杭直径 $d$ との比 $l / d$ が 1.5 以上であ れば,これをほとんど無視してよい。

このように考えれば，各杭に対してその周面上の代表 的な 2 点に㧍ける地盤と杭との変位が等しくなるように 末定係数を定めればよいことになる．いまこの 2 点を， 図一1 に示すように $C_{i}, D_{i}(i=1,2, \cdots, N)$ に選べば, 式 (13)，(14）と式（24）を用いて, 上述の境界条件は 次式のように表わせる.

$$
\begin{aligned}
& \left.\xi_{P i}\right|_{\substack{r_{i}=a_{i} \\
\theta_{i}=0}}+\left.\sum_{j \neq i} \xi_{P j}\right|_{\substack{r_{i}=0 \\
\theta_{i}=0}}=w_{i}^{x}(z)
\end{aligned}
$$

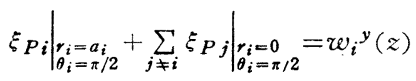

$$
\begin{aligned}
& \left.\zeta_{P i}\right|_{\substack{r_{i}=a_{i} \\
\theta_{i}=0}}+\left.\sum_{j \neq i} \zeta_{P}\right|_{\substack{r_{i}=0 \\
\theta_{i}=0}}=w_{i}^{y}(z) \\
& \left.\zeta_{P i}\right|_{\substack{r_{i}=a_{i} \\
\theta_{i}=\pi / 2}}+\left.\left.\sum_{j \neq i} \zeta_{P}\right|_{j}\right|_{\substack{r_{i}=0 \\
\theta_{i}=\pi / 2}}=-w_{i}^{x}(z) \\
& (i=1,2, \cdots, N)
\end{aligned}
$$

ここで, 式 (30) と（33）および式 (31) と（32）か らそれぞれ次の関係式が成り立つことが導かれる.

$$
\left.\begin{array}{r}
U_{m}^{j x}\left(a_{j}\right)+V_{m}^{j x}\left(a_{j}\right)=0 \\
U_{m}^{j y}\left(a_{j}\right)+V_{m}^{j y}\left(a_{j}\right)=0
\end{array}\right\} \cdots \cdots
$$

したがって, 式（15）を参照すれば,

$$
\left.\begin{array}{l}
B_{m}^{i x}=-\psi_{m}^{i} A_{m}^{i x} \\
B_{m}^{i y}=-\psi_{m}^{i} A_{m}^{i y}
\end{array}(i=1,2, \cdots, N)\right\} .
$$

が得られる.ここに，

$$
\psi_{m}^{i}=\frac{\eta_{a i} K_{2}\left(\eta_{a i}\right)}{\psi_{a i} K_{2}\left(\psi_{a i}\right)} \quad(i=1,2, \cdots, N)
$$

とおいた.

なお, 式 (34) の関係は, 式 (13)，(14）を用いて各 杭において杭周面と接している地盤は，杭の変形後も円 形を保たねばならないといら条件からもこれを導くこと ができる.

さて，式 (35) の関係を用いれば, 結局, 式 (30)，(31) は次のように表わすことができる.

$$
\begin{aligned}
& Y_{m}^{i x}+\left\{K_{1}\left(\eta_{a i}\right)+\psi_{m}{ }^{i} K_{1}\left(\psi_{a i}\right)-\eta_{a i} K_{2}\left(\eta_{a i}\right)\right\} A_{m}{ }^{i x} \\
& -\sum_{j \neq i} \frac{1}{\eta_{r j i}}\left[\eta_{a i} \eta_{r i j} K_{2}\left(\eta_{a i} \eta_{r i j}\right) \cos ^{2} \theta_{i j}\right. \\
& +\psi_{m}^{j} \psi_{a i} \psi_{r i j} K_{2}\left(\psi_{a i} \psi_{r i j}\right) \sin ^{2} \theta_{i j} \\
& \left.-K_{1}\left(\eta_{a i} \eta_{r i j}\right)-\psi_{m}{ }^{j} K_{1}\left(\psi_{a i} \psi_{r i j}\right)\right] A_{m}{ }^{j x} \\
& -\sum_{j \neq i} \frac{1}{\eta_{r j i}}\left[\left\{\eta_{a i} \eta_{r i j} K_{2}\left(\eta_{a i} \eta_{r i j}\right)\right.\right. \\
& \left.\left.-\psi_{m}{ }^{j} \psi_{a i} \psi_{r i j} K_{2}\left(\psi_{a i} \psi_{r i j}\right)\right\} \sin \theta_{i j} \cos \theta_{i j}\right] A_{m}{ }^{j y} \\
& =0 \text {. } \\
& Y_{m}^{i y}+\left\{K_{1}\left(\eta_{a i}\right)+\psi_{m}{ }^{i} K_{1}\left(\psi_{a i}\right)-\eta_{a i} K_{2}\left(\eta_{a i}\right)\right\} A_{m}{ }^{i y} \\
& -\sum_{j \neq i} \frac{1}{\eta_{r j i}}\left[\left\{\eta_{a i} \eta_{r i j} K_{2}\left(\eta_{a i} \eta_{r i j}\right)\right.\right. \\
& \left.\left.-\psi_{m}^{j} \psi_{a i} \psi_{r i j} K_{2}\left(\psi_{a i} \psi_{r i j}\right)\right\} \sin \theta_{i j} \cos \theta_{i j}\right] A_{m}^{j x} \\
& -\sum_{j \neq i} \frac{1}{\eta_{r j i}}\left[\eta_{a i} \eta_{r i j} K_{2}\left(\eta_{a i} \eta_{r i j}\right) \sin ^{2} \theta_{i j}\right. \\
& +\psi_{m}^{j} \phi_{a i} \psi_{r i j} K_{2}\left(\psi_{a i} \psi_{r i j}\right) \cos ^{2} \theta_{i j} \\
& \left.-K_{1}\left(\eta_{a i} \eta_{r i j}\right)-\psi_{m}{ }^{j} K_{1}\left(\psi_{a i} \psi_{r i j}\right)\right] A_{m}^{j y}=0 \\
& (i=1,2, \cdots, N)
\end{aligned}
$$

\section{（7）変位の影響係数}

変位の影響係数 $\delta_{i j}{ }^{x y}$ 等を得るためには, 未定係数 $A_{m}{ }^{i x}, Y_{m}{ }^{i x}$ 等を定めることが必要である. $i$ 杭がその 杭頭に $x$ 方向の単位水平荷重を受けた場合について考え ると, 式 (27)，(28) および式 (37)，(38) を用いて $m=$ $1,2, \cdots$ に対して, それぞれ未定係数 $A_{m}^{i x}, Y_{m}^{i x}$ 等に 関する連立一次方程式を立てて，これを解けばよい。こ のとき採用すべき $m$. の值は，必要な精度を考慮して適 当に定める.

$Y_{m}^{i x}$ 等が得られれば, 変位の影響係数は, 式 (24)を 用いて次式によってこれを求めることができる. 


$$
\left.\begin{array}{rl}
\delta_{j i}{ }^{x x}=w_{j}{ }^{x}(H) & =\sum_{m=1,3,5, \cdots}^{\infty}(-1)^{(m-1) / 2} Y_{m}{ }^{j x} \\
\delta_{j i}{ }^{y x}=w_{j}^{y}(H) & =\sum_{m=1,3,5, \cdots}^{\infty}(-1)^{(m-1) / 2} Y_{m}{ }^{j y}
\end{array}\right\}
$$

次に, 同様にして上述の手順を各杭 $(i=1,2, \cdots, N)$ について繰返せば，結局各杭に対する影響係数がすべて 求められる. したがって, 式 (1) を用いて $Q_{i}{ }^{x}, Q_{i}{ }^{y}(i$ $=1,2, \cdots, N)$ を得ることができる. $Q_{i}{ }^{x}, Q_{i}{ }^{y}$ が得ら れれば, 式 (2) より多柱基礎の $x$ 方向群杭効果を求め ることができる. なお, 式 (2) 中の $Q_{i 0}$ は式 (4) を用 いれば次式によって与えられる。

$$
\begin{aligned}
Q_{i 0}= & \frac{1}{w_{i}(H)}=\frac{\pi^{4} E_{i} I_{i}}{32 H^{3}} \mid \\
& \left\{\sum_{m=1,3,5, \ldots m^{4}\left(1+\alpha_{i} m^{-2} \Omega_{m}{ }^{i}\right)}^{\infty}\right\}
\end{aligned}
$$

ここに,

$$
\begin{array}{r}
\Omega_{m}^{i}=\frac{K_{1}\left(\eta_{a i}\right)+\psi_{m}{ }^{i} K_{1}\left(\psi_{a i}\right)}{K_{1}\left(\eta_{a i}\right)+\eta_{a i} K_{0}\left(\eta_{a i}\right)-\psi_{m}{ }^{i} K_{1}\left(\psi_{a i}\right)} \\
(i=1,2, \cdots, N) \cdots \cdots \cdots \cdots
\end{array}
$$

$Q_{i 0}$ はまた, 単杭の杭頭ばね定数とよんでもよい. 単 杭の杭頭抵抗力に対する群杭を構成する各杭の杭頭抵抗 力の比は,

$$
\begin{aligned}
& f_{i}{ }^{x x}=\frac{Q_{i}^{x}}{Q_{i 0}}, f_{i}{ }^{y x}=\frac{Q_{i}^{y}}{Q_{i 0}} \\
&(i=1,2, \cdots, N)
\end{aligned}
$$

によって与えられる・

さらに, 各杭に対する荷重方向 ( $x$ 方向) の荷重分担 率は,

$$
\begin{array}{r}
v_{i}^{x}=Q_{i}^{x} / \sum_{i=1}^{N} Q_{i}{ }^{x} \\
(i=1,2, \cdots, N)
\end{array}
$$

と表わせる.

$y$ 方向の群杭効果についてもまったく同様にしてこれ を求めることができる.

いま述べた方法に従えば, 1 本の杭について未定係数
は 4 個必要であるから，この未定係数を定める連立一次 方程式の元数は $4 N$ 元となり, $4 N$ 元の連立一次方程 式を $m=1,2, \cdots$ について解くことが必要である.

式 (27) と（37）抽式 (28) と（38）から $Y_{m}^{i x}$, $Y_{m}{ }^{i y}$ を消去すれば, 杭 1 本については 2 個の未定係数 $A_{m}{ }^{i x}, A_{m}{ }^{i y}$ のみになるから, 結局, $2 N$ 元の連立一次 方程式を解けばよいことになる.しかし，この場合は， 直接には $Y_{m}{ }^{i x}, Y_{m}{ }^{i y}$ が得られないから，影響係数を 求めるための計算量が増すことになる.

いずれにしても, 杭本数の 4 倍あるいは 2 倍の元数を もつ連立一次方程式を解けば, 群杭の横方向群杭効果を 容易に求めることができる.さらに本論の方法は，前論 のそれのように煩雑で見通しの悪い計算方法と異なり， 一定の規則で上述の連立方程式の各係数を簡単に定める ことができるので, 杭配置が不規則であったり，杭径が 互いに異なっているような円柱群から構成された群杭の 群杭効果をも容易に解析することができる.

\section{3. 数値計算結果および実験值との比較}

図一2（a)〜 (c) は著者等が模型杭を用いて行った実 験結果 ${ }^{5)}$ と本論によって求めた理論值とを対比したもの である. 同図は横軸に最小の杭中心点間距離 $l$ と杭直径 dとの比をとって群杭効果を表わした. 縦軸の群杭効果 を示す記号 $e$ の下つき添字は杭本数を, 上つき添字は 荷重方向を示す.

実験については前論らにおいて詳細に述べているが, いま一度ここで実験装置（図一3 参照）ならびに実験方 法について簡単に述べると次のとおりである.

振動台上にのせた $1.5 \mathrm{~m} \times 2.5 \mathrm{~m} \times 1 \mathrm{~m}$ (深さ) の鋼製 箱の中に深さ $60 \mathrm{~cm}$ まで乾燥砂を入れて, 模型杭を建 て込み，杭頭に水平荷重を加える. そしてそのときの水 平荷重と杭頭の水平変位および回転変位を計測した. 荷 重はひずみリングに貼付したひずみゲージを用いて，変

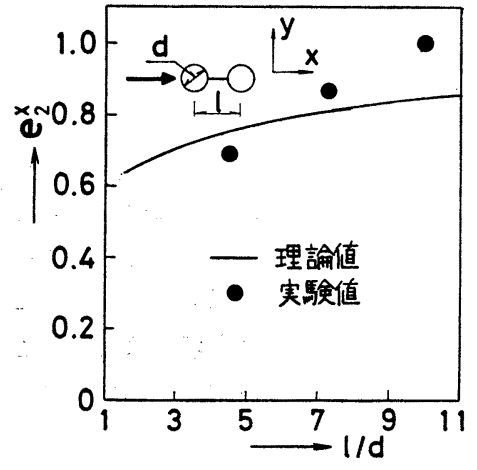

(a) 2 本杭

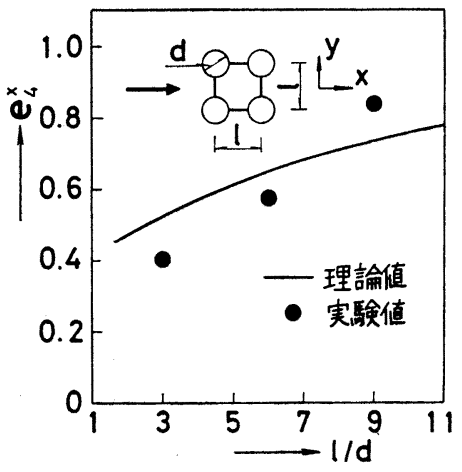

(b) 4 本杭

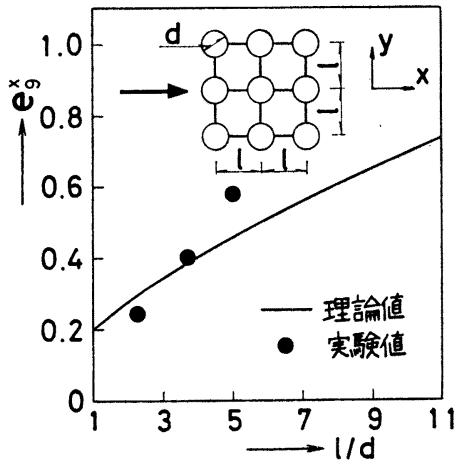

(c) 9 本杭

図一2 群杭効果の理論値と実験值 $\left(\alpha_{0}=1.4 \times 10^{-4}, \nu=0.3, H / d=50.0\right)$ 


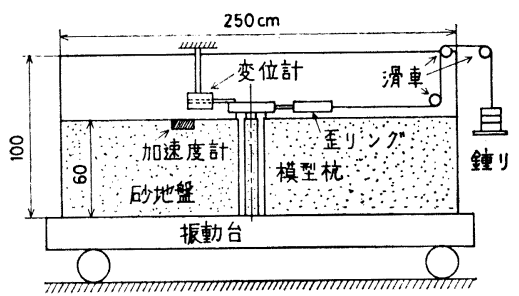

図一3 実験装圈

位は差動トランス型変位計を用いて計測を行い,これら を電磁オッシログラフに記録した.

実験は杭頭を完全回転拘束の状態にして, $2,4,9$ 本 杭の 3 通りの場合について, それぞれ杭間隔をいろいろ 変えて行った.

模型杭としてはベークライトチューブを用いた．杭の 形状は円形で, 外径 $12 \mathrm{~mm}$, 肉厚 $2 \mathrm{~mm}$, 長さ $60 \mathrm{~cm}$ である.また，曲げ剛性は $1.45 \times 10^{4} \mathrm{~kg} \cdot \mathrm{cm}^{2}$ であった。 頂板は $15 \mathrm{~cm} \times 15 \mathrm{~cm} \times 2.3 \mathrm{~cm}$ (厚さ) の鋼製板で, 所定 の杭間隔を示す位置にボルト穴があけてある.

実験に用いた砂地盤のせん断弾性定数は $20 \mathrm{~kg} / \mathrm{cm}^{2}$ で あった.

それぞれの実験について, できるだけ一様な砂地盤が 得られるように, 模型杭を砂地盤中に建て込んだ後, 砂 地盤を常に一定の条件で, 寸なわちその表面における加 速度が $500 \mathrm{gal} \mathrm{になるようにして} 10 \mathrm{~Hz}$ で 12 分間加
振して締め固めを行った.

群杭効果 $e$ を求めるためには, 単杭についてその杭 頭における荷重と変位の関係が必要である. 単杭に対し てその杭頭の回転を拘束した状態のまま水平荷重を加え て, 杭頭水平変位を測定することは, 実験的には非常に 困難である. 本実験においては 2 本杭について, 両杭の 間隔をできるだけ大きく（いまの場合 $l / d=10$ を採用し た）とって実験を行い，このとき得られた水平荷重の $1 / 2$ と水平変位との関係を単杭に対する荷重一変位曲線と して用いた.

実験は砂地盤が弾性変形をする範囲で行ったので, 杭 頭変位の計測は非常に小さな領域 $(0 \sim 60$ ミクロン) で 行う必要があった. また, 杭の砂地盤への建込みが各実 験ごとに一様になるようにすることが非常に難かしく， 実験值には多少のばらつきが生じた.

同一の杭配置に対して実験を 3 回行い, それぞれの荷 重一変位曲線から その勾配を求めて 3 者の平均值を求め た. 図一2（a)〜 (c) はその結果を示したものである.

杭本数が少なく, 杭間隔が小さい場合には実験值のば らつきが大きくなる傾向があった.

以上のことを考慮すれば, いずれの場合も理論值は実 験值に比較的よく一致しているといえよう. 実験值は, 理論值と比べて一般に, 杭相互間に働く影響の大きさ が, $l / d$ が大きくなるに従ってより早く減少する傾向を

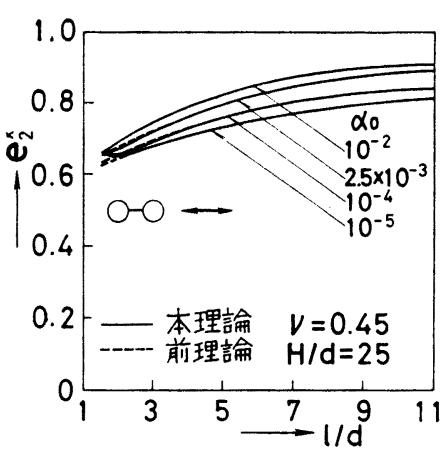

(a) 2 本杭, $x$ 方向

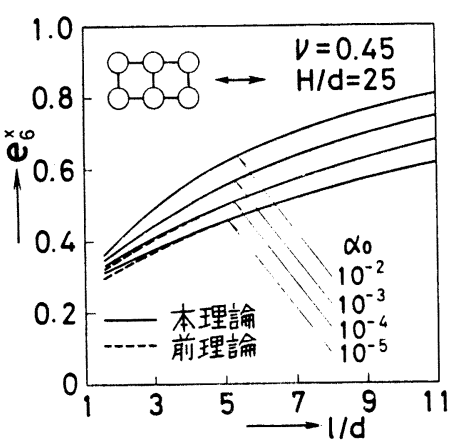

(d) 6 本杭， $x$ 方向

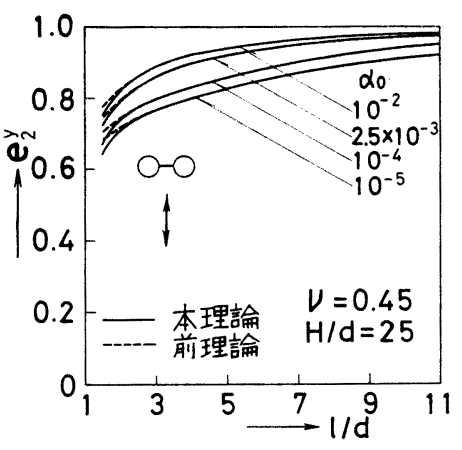

(b) 2 本杭, $y$ 方向

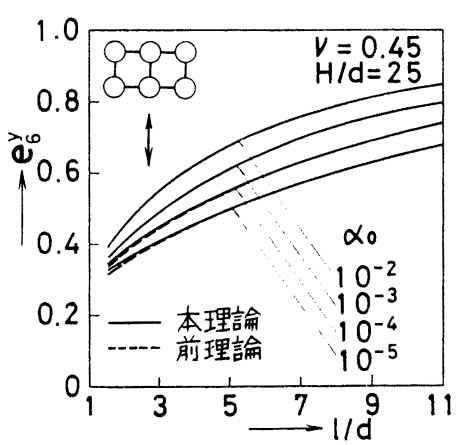

(e) 6 本杭, $y$ 方向

図一4群杭奻果

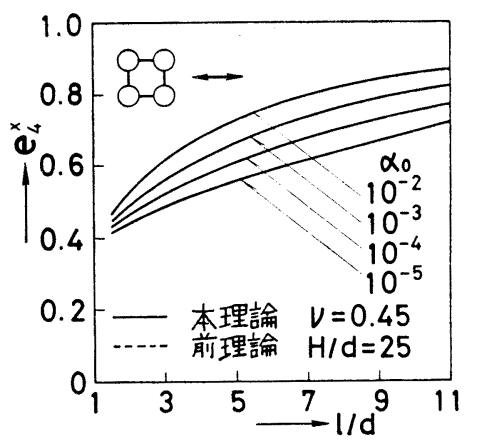

(c) 4 本杭

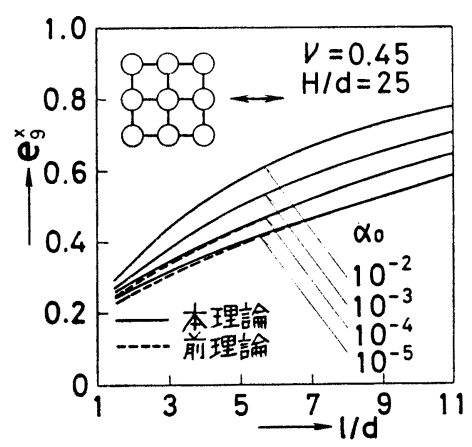

(f) 9 本杭 
示している.

杭および地盤の剛性, 杭配置等をいろいろ変えた場合 について,それぞれ前論 ${ }^{1)}$ の方法と本論の方法とに従っ て行った数值計算結果の一例を 図一4(a)〜 (f) に示し た. 図中 $\alpha_{0}$ は地盤のせん断弾性係数と杭の曲げ岡性と の関係を表わす定数で, 次のように定義した.

$$
\alpha_{0}=\frac{\mu I_{0}}{E I}, \quad I_{0}=\frac{\pi}{64} d^{4}
$$

なお, 数值計算においては, $m$ に関する無限級数の 和を求めることが必要であるが，本論では $m=1,3,5$, $\cdots, 99$ ，すなわち 50 項までの和を採用した. 計算時間 については，それぞれの場合で多少の違いがあるので一 概にはいえないが, 本論の場合は前論の場合に比べて約 半分の時間しかかからないといってよいようである.

図一4において, 実線が本論による計算結果を, 点線

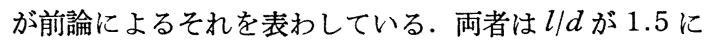
近い場合を除いてほとんど一致している.また，杭本数 の多い場合, 図一4 (d)〜 (f) に現われた両者の差は, 前論の計算方法において次のような近似的取扱いをした ことによって生じたものである. すなわち， $N$ 本の杭 を 2 本ずつ $N(N-1) / 2$ 組の組合せに分けて, この 2 本 の杭の間についてだけ前論の方法における境界条件の補 正を遂次行って, これらの結果を重ね合わせて $N$ 本杭 の群杭効果を求めた. したがって, いま選んだ 2 本の杭 に対する他の杭の影響はこれをまったく無視したことに なる.このようにすれば, 当然杭間隔が小さくなるほど その誤差は大きくなる.

\begin{tabular}{|c|c|}
\hline $1 \times 2$ & $\Theta^{0.66} \Theta^{0.66}$ \\
\hline $2 \times 1$ & $\begin{array}{l}O^{0.75} \\
.0 .75\end{array}$ \\
\hline $2 \times 2$ & $\begin{array}{l}1^{0.47} Q^{0.47} \\
\circ \\
0 \\
0 \\
0.47 \\
0 \\
0.47\end{array}$ \\
\hline $2 \times 3$ & 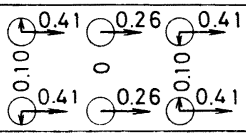 \\
\hline $3 \times 2$ & 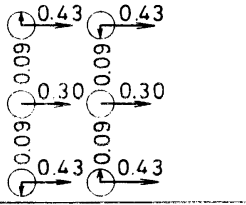 \\
\hline $3 \times 3$ & 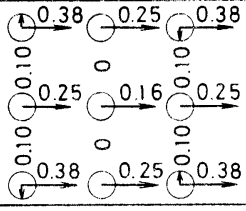 \\
\hline
\end{tabular}

図-5 $f_{i}\left(\nu=0.45, H / d=25, a_{0}=10^{-5}, l / d=2.5\right.$ の場合 $)$
図一5 は 2, 4, 6, 9 本杭について, 式 (42) によっ て求めた $f_{i}{ }^{x x}, f_{i}{ }^{y x}$ (単杭の杭頭抵抗力に対する群杭 を構成する各杭の杭頭抵抗力の比）の一例を示したもの である. $l / d=2.5$ のときは, 荷重直角方向の $f_{i}{ }^{y x}$ は $\max \left(f_{1}{ }^{x x},{f_{2}}^{x x}, \cdots, f_{N}{ }^{x x}\right)$ の約 $1 / 4$ であることがわ かる.

この $f_{i}{ }^{x x}, f_{i}{ }^{y x}$ は $l / d$ によっても変化するし, さら に各杭についてその変化の傾向は異なっている. 図一6 (a), (b) に6 本杭および 9 本杭について, その構成各 杭の $f_{i}{ }^{x x}, f_{i}{ }^{y x}$ の $l / d$ に対する変化を示した. 図中

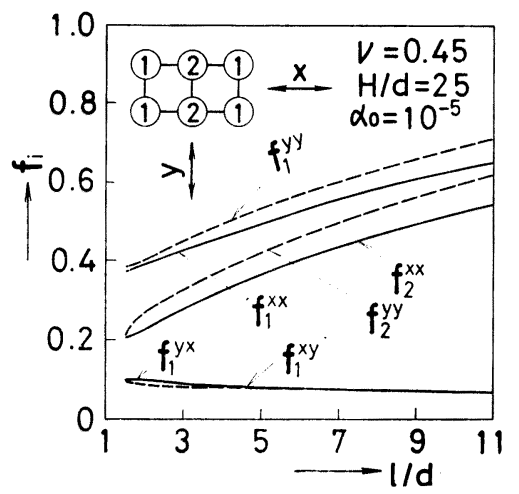

(a) 6 本杭

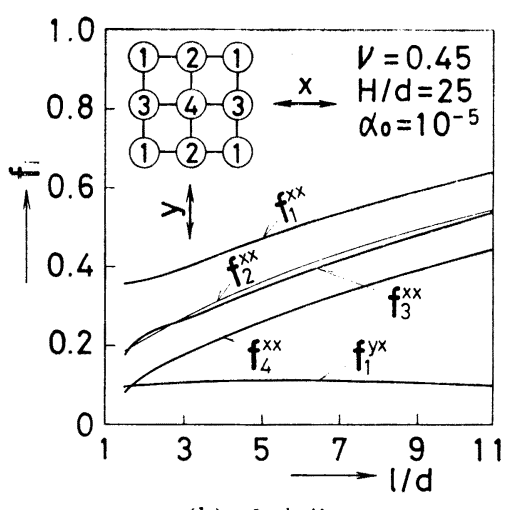

(b) 9 本杭

图一 $6 \boldsymbol{f}_{i}$ の変化

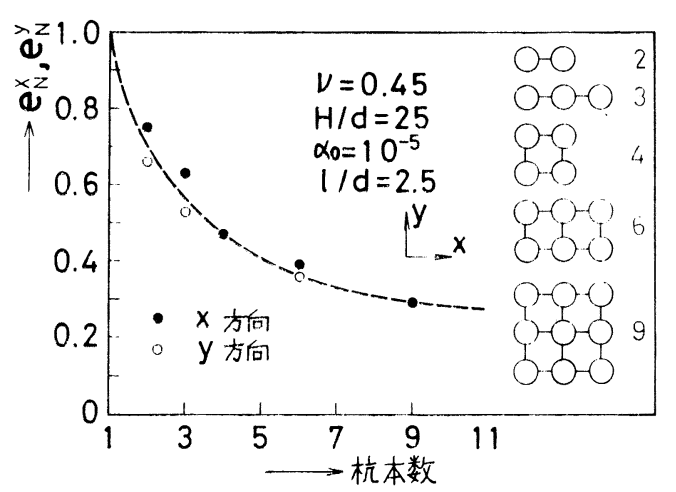

図一7 杭本数と群杭効果 
$f_{i}{ }^{y x}$ は群杭が $x$ 方向荷重をうけたときの $i$ 杭の $y$ 方 向の杭頭抵抗力の比を表わす. 荷重直角方向の $f_{i}{ }^{\boldsymbol{y}}$ は いずれの場合もほぼ一定とみなしてよい。

図一7 は群杭を構成する杭本数と群杭効果の関係を, 一例として $l / d=2.5$ の場合について示した.

\section{4. おわりに}

以上に詳論したように，本論の解析法はその結果にお いて前論のそれとの間にほとんど差はみとめられない が，解析法自身についてはその見通しのよさと簡潔さ， さらには不規則な杭配置および種々の杭径に対しても， そのために解法上に特別な考虑を必要とせず，一定の手 順に従って数值計算が行えるといら一般性のある点で本 論の解析法はまさっているといえる.すなわち，本論の 見通しのよさと簡潔さおよび一般性は，式 (27)，(28)， (37)，(38）で示される $4 N$ 元の連立一次方程式を作成 して,これを解くことによって群杭を構成する各杭の荷 重分担力および群杭効果を容易に求めることができると ころにある。

付録 I 式 (18)'，(19）'に現われる積分

$$
\text { (1) } I_{1}=\int_{-\pi}^{\pi}\left[K_{3}\left(\eta_{a j} \eta_{r j}\right) \cos \left(3 \theta_{j}-\theta_{i}\right)\right]_{r_{i}=a_{i}} d \theta_{i}
$$

について

図一1 を参照すれば, $i, j$ 座標の間には次の関倸式が 成立する.

$$
\left.\begin{array}{l}
r_{i} \sin \left(\theta_{i}-\theta_{i j}\right)=r_{j} \sin \left(\theta_{j}-\theta_{i j}\right) \\
r_{i} \cos \left(\theta_{i}-\theta_{i j}\right)=r_{i j}+r_{j} \cos \left(\theta_{j}-\theta_{i j}\right) \\
r_{i} \cos \theta_{i}=r_{i j} \cos \theta_{i j}+r_{j} \cos \theta_{j} \\
r_{i} \sin \theta_{i}=r_{i j} \sin \theta_{i j}+r_{j} \sin \theta_{j} \\
{r_{j}}^{2}=r_{i j}{ }^{2}+r_{i}{ }^{2}-2 r_{i j} r_{i} \cos \left(\theta_{i}-\theta_{i j}\right)
\end{array}\right\}
$$

いま, 式 (I-1) の積分の積分範囲を $(-\pi, \pi)$ から $\left(-\pi+\theta_{i j}, \pi+\theta_{i j}\right)$ に変え, さらに積分変数を $\theta_{i}$ から $\theta=\theta_{i}-\theta_{i j}$ に変換すれば, $r_{i}=a_{i}$ とおいたとき $K_{3}\left(\eta_{a j}\right.$ $\left.\cdot \eta_{r j}\right)$ は $\theta$ に関して偶関数であるから, 積分 $I_{1}$ を計算 するためには $\cos \left(3 \theta_{j}-\theta_{i}\right)$ を奇関数と偶関数に分けて， その偶関数部のみを考えればよい. 式 ( I - 2) を参照す れば,

$\cos \left(3 \theta_{j}-\theta_{i}\right)$ の偶関数部

$$
\begin{aligned}
= & \frac{1}{r_{j}{ }^{3}}\left\{a_{i}{ }^{3} \cos 2 \theta-r_{i j}\left(3 a_{i}{ }^{2}+r_{i j}{ }^{2}\right) \cos \theta\right. \\
& \left.+3 a_{i} r_{i j}{ }^{2}\right\} \cos 2 \theta_{i j} \ldots \ldots \ldots \ldots \ldots \ldots \ldots \ldots \ldots \ldots \ldots \ldots \ldots
\end{aligned}
$$

一方, 数学公式 III ${ }^{6)}$ 加,

$$
\frac{K_{3}\left(\eta_{a j} \eta_{r j}\right)}{r_{j}{ }^{3}}=\frac{\eta_{a i}{ }^{3}}{a_{i}{ }^{3}} \frac{K_{3}\left(\eta_{a j} \eta_{r j}\right)}{\eta_{a i}{ }^{3} \eta_{r j}{ }^{3}}
$$

$$
\begin{aligned}
& =\frac{\eta_{a i}{ }^{3}}{a_{i}{ }^{3}} \cdot 8 \Gamma(3) \sum_{n=0}^{\infty}(n+3) C_{n}{ }^{3}(\cos \theta) \\
& \cdot \frac{K_{n+3}\left(\eta_{a i} \eta_{r i j}\right)}{\eta_{a i}{ }^{3} \eta_{r i j}{ }^{3}} \cdot \frac{I_{n+3}\left(\eta_{a i}\right)}{\eta_{a i}{ }^{3}}
\end{aligned}
$$

ここに, $C_{n}{ }^{3}(\cos \theta)$ は Gegenbauer の多項式で,

$$
\begin{aligned}
C_{n}{ }^{3}(\cos \theta)= & \sum_{\kappa=0}^{n} \frac{\Gamma(3+\kappa) \Gamma(n+3-\kappa)}{\kappa !(n-\kappa) !\{\Gamma(3)\}^{2}} \\
& \cdot \cos (2 \kappa-n) \theta \ldots \ldots \ldots \ldots \ldots \ldots
\end{aligned}
$$

である. また, $\Gamma(\kappa)$ はガンマ関数, $I_{n}\left(\eta_{a i}\right)$ は第 1 種 第 $n$ 次の変形ベッセル関数である.さらに,

$$
\eta_{r i j}=\frac{r_{i j}}{a_{i}}
$$

とおいた.

いま，式（I-3）と式（I-5）とから次の積分を計算 すると

$$
\begin{aligned}
& \int_{-\pi}^{\pi} C_{n}{ }^{3}(\cos \theta)\left\{a_{i}{ }^{3} \cos 2 \theta-r_{i j}\left(3 a_{i}{ }^{2}+r_{i j}{ }^{2}\right) \cos \theta\right. \\
& \left.+3 a_{i} r_{i j}{ }^{2}\right\} d \theta \\
& =\left\{\begin{array}{cc}
\frac{\pi}{2}(k+1)(k+2) a_{i}\left\{k(k+3) a_{i}{ }^{2}\right. \\
\left.+3(k+1)(k+2) r_{i j}{ }^{2}\right\} & (n=2 k \text { のとき }) \\
-\frac{\pi}{2} k(k+1)^{2}(k+2)\left(3 a_{i}{ }^{2}+r_{i j}{ }^{2}\right) r_{i j} & (n=2 k-1
\end{array}\right\}
\end{aligned}
$$

であるから, 結局, 求める積分 $I_{1}$ は,

$$
I_{1}=2 \pi F\left(\eta_{a i}, \eta_{r i j}\right) \cos 2 \theta_{i j}
$$

と表わせる．ここに，

$$
\begin{gathered}
F\left(\eta_{a}, \eta_{r}\right)=\frac{4}{\eta_{a}^{2} \eta_{r}^{2}} \sum_{k=0}^{\infty}[(k+1)(k+2)(2 k+3)\{k(k+3) \\
\left.+3(k+1)(k+2) \eta_{r}{ }^{2}\right\} \frac{K_{2 k+3}\left(\eta_{a} \eta_{r}\right)}{\eta_{a} \eta_{r}} I_{2 k+3}\left(\eta_{a}\right) \\
-2 k(k+1)^{3}(k+2)\left(3+\eta_{r}{ }^{2}\right) \\
\left.\cdot K_{2 k+2}\left(\eta_{a} \eta_{r}\right) \frac{I_{2 k+2}\left(\eta_{a}\right)}{\eta_{a}}\right] \cdots \cdots \cdots \cdots \cdots(I-9)
\end{gathered}
$$

(2) $I_{2}=\int_{-\pi}^{\pi}\left[K_{3}\left(\eta_{a j} \eta_{r j}\right) \sin \left(3 \theta_{j}-\theta_{i}\right)\right]_{r_{i}=a_{i}} d \theta_{i}$

について

（1）の場合と同様にすれば,

$$
I_{2}=2 \pi F\left(\eta_{a i}, \eta_{r i j}\right) \sin 2 \theta_{i j}
$$

を得る。

（3）式 (18)'，(19)'に現われる他の積分について も，(1）とまったく同様に考えればよい．以下に結果の みを示す。

$$
\begin{aligned}
I_{3} & =\int_{-\pi}^{\pi}\left[K_{1}\left(\eta_{a j} \eta_{r j}\right) \cos \left(\theta_{j}-\theta_{i}\right)\right]_{r_{i}=a_{i}} d \theta_{i} \\
& =-2 \pi I_{1}\left(\eta_{a i}\right) K_{0}\left(\eta_{a i} \eta_{r i j}\right) \cdots \cdots \cdots \cdots \cdots \cdots
\end{aligned}
$$




$$
\begin{aligned}
& I_{4}= \int_{-\pi}^{\pi}\left[K_{1}\left(\eta_{a j} \eta_{r j}\right) \sin \left(\theta_{j}-\theta_{i}\right)\right]_{r_{i}=a_{i}} d \theta_{i}=0 \\
& \ldots \ldots \ldots \ldots \ldots \ldots \ldots \ldots(\mathrm{I}-13) \\
& I_{5}= \int_{-\pi}^{\pi}\left[K_{1}\left(\eta_{a j} \eta_{r j}\right) \cos \theta_{j} \cos \theta_{i}\right]_{r_{i}=a_{i}} d \theta_{i} \\
&=-\pi I_{1}\left(\eta_{a i}\right)\left\{K_{0}\left(\eta_{a i} \eta_{r i j}\right)\right. \\
&\left.+K_{2}\left(\eta_{a i} \eta_{r i j}\right) \cos 2 \theta_{i j}\right\} \cdots \ldots \ldots \ldots(\mathrm{I}-14) \\
& I_{6}= \int_{-\pi}^{\pi}\left[K_{1}\left(\eta_{a j} \eta_{r j}\right) \cos \theta_{j} \sin \theta_{i}\right]_{r_{i}=a_{i}} d \theta_{i} \\
&= \int_{-\pi}^{\pi}\left[K_{1}\left(\eta_{a j} \eta_{r j}\right) \sin \theta_{j} \cos \theta_{i}\right]_{r_{i}=a_{i}} d \theta_{i} \\
&=-\pi I_{1}\left(\eta_{a i}\right) K_{2}\left(\eta_{a i} \eta_{r i j}\right) \sin 2 \theta_{i j} \ldots \ldots(\mathrm{I}-15) \\
& I_{7}= \int_{-\pi}^{\pi}\left[K_{1}\left(\eta_{a j} \eta_{r j}\right) \sin \theta_{j} \sin \theta_{i}\right]_{r_{i}=a_{i}} d \theta_{i} \\
&= \pi I_{1}\left(\eta_{a i}\right)\left\{-K_{0}\left(\eta_{a i} \eta_{r i j}\right)\right.
\end{aligned}
$$$$
\left.+K_{2}\left(\eta_{a i} \eta_{r i j}\right) \cos 2 \theta_{i j}\right\}
$$$$
\text { 萦考文 献 }
$$

1）小坪清真・高西照彦 : 横方向群杭効果の理論的考察, 土 木学会論文報告集, No. 241, 1975.9.

2) Penzien, J., C.F. Scheffey and R.A. Parmellee : Seismic analysis of bridges on long piles, Proc. A.S.C. E., Vol. 90, No. EM 3, 1964.

3）杉村義広：群ぐい基礎に扝ける水平地盤係数の低减効果, 第 7 回土質工学研究発表会, 昭 47.6.

4) Poulos, H.G. : Behavior of laterally loaded piles IIPile groups, Proc. A.S.C.E., Vol. 97, No. SM 5, 1971.

5）小坪清真 - 高西照彦 - 河島正治 : 横方向群杭効果敒関す る模型実験, 土木学会論文報告集 研究ノ一ト, No. 248, 1976.4.

6) 森口繁一. 宇田川銈久. 一松 信 : 数学公式 III, 岩波全 書.

(1977.7.25 - 受付) 